\title{
A Review on Grid-Connected PV System
}

\section{Anjali}

M.Tech Scholar, Electrical Engineering Department R.P. Inderaprastha Institute of Technology, Karnal

\section{Gourav Sharma}

Assis Professor, Electrical Engineering Department R.P. Inderaprastha Institute of Technology, Karnal

\section{ABSTRACT}

The concept of injecting photovoltaic power into the utility grid has earned widespread acceptance in these days of renewable energy generation $\&$ distribution. Grid-connected inverters have evolved significantly with high diversity. Efficiency, size, weight, reliability etc. have all improved significantly with the development of modern and innovative inverter configurations and these factors have influenced the cost of producing inverters.

This paper presents a literature review of the recent technological developments and trends in the GridConnected Photovoltaic Systems (GCPVS). In countries with high penetration of Distributed Generation (DG) resources, GCPVS have been shown to cause unwanted stress on the electrical grid. A review of the existing and future standards that addresses the technical challenges associated with the growing number of GCPVS is presented. Maximum Power Point Tracking (MPPT), Solar Tracking (ST) and the use of transform-less inverters can all lead to high efficiency gains of Photovoltaic (PV) systems while ensuring minimal interference with the grid. Inverters that support ancillary services like reactive power control, frequency regulation and energy storage are critical for mitigating the challenges caused by the growing adoption of GCPVS.

Keywords: Grid connected power system, Photovoltaic System, Maximum Power Point Tracking System, style, Solar Tracking, Totla Harmonic Distortions

\section{INTRODUCTION}

Renewable energy is increasingly considered essential for meeting current and future energy needs [1]. Photovoltaic (PV) power, as it is clean and unlimited source of energy, is probably the best technology amongst all renewable energy sources and therefore a considerable amount of research has been conducted recently in this field. To better utilize the PV power, grid interconnection of PV system is needed. PV power rendering to the utility grid has been the fastest growing renewable energy technology by far since it attracted the attention of policy makers [2].

It is generally accepted in the scientific community that human activity is affecting climate change and that a majority of this impact comes from fossil fuel combustion caused by the electric utility industry. In $2012,32 \%$ of the total greenhouse gas emissions in the U.S. was from the electric power industry, the highest of all sectors. Conventional fossil-fuel generating facilities have in past met the majority of global electrical energy demands. However, environmental and climate change implications of fossil fuel-based generation present serious challenges to society and the environment. Distributed Generation (DG), particularly Photovoltaic (PV) systems, provides a means of mitigating these challenges by generating electricity directly from sunlight. Unlike off-grid PV systems, Grid-Connected Photovoltaic Systems (GCPVS) operate in parallel with the electric utility grid and as a result they require no storage systems. Since GCPVS supply power back to the grid when producing excess electricity (i.e., when generated power is greater than the local load demand), GCPVS help offset greenhouse gas emissions by displacing the power needed by the connected (local) load and providing additional electricity to the grid. As such, during peak solar hours (maximum solar irradiance), fewer conventional generation plants are needed. In addition, GCPVS reduce Transmission and Distribution (T\&D) losses. Although average T\&D losses amounted to $5.7 \%$ in the U.S. in 2010, losses during peak hours are higher [3]. For example, the estimated T\&D losses for Southern California Edison and Pacific Gas \& Electric exceeded 10\% in 2010 [4]. 
Locating DG assets close to loads can help to partially mitigate these losses.

In this paper, we focus our attention on the growing adoption of GCPVS and the technical challenges posed by the mass proliferation of these DG systems on the overall performance and reliability of the electric grid. A review of the standards governing the safe installation, operation and maintenance of GCPVS, and the known methods of improving efficiency of PV systems are presented. Some transformer-less topologies based on half-bridge, fullbridge configuration and multilevel concept, and some soft-switching inverter topologies are remarked as desirable for grid-connected single-phase PV inverters with respect to high efficiency, low cost, and compact structure. We also focus on the role of the inverter as an active grid participant. Inverters designed with the ability to support electric grid ancillary services will become the norm in the foreseeable future, especially in light of the growing number of small and large-scale GCPVS that are being brought on-line.

\section{STANDARDS AND SPECIFICATIONS OF GRID-CONNECTED PV INVERTER}

The Distribution Network Operators are responsible for providing safe, reliable and good quality electric power to its customers. The PV industry needs to be aware of the issues related to safety and power quality and assist in setting standards as this would ultimately lead to an increased acceptance of the grid-connected PV inverter technology by users and the electricity utility industry. And for the system to be operated safely and reliably, these standards must be adopted, which will cater to build electricity consumer's trust, reduce costs and further flourish grid-connected PV inverter development. There are several standards on the market dealing with the interconnection of PV energy sources with the utility grid like International Electro technical Commission (IEC), Institute of Electrical and Electronics Engineers (IEEE) and National Electrical Code (NEC).

These standards fix the limits for the inverter voltage changes, its operating frequency changes, power factor, harmonics in the current injected into grid, injection of DC current into the grid to avoid distribution transformers saturation [5] and also address grounding issue. These also contain information regarding islanding of PV systems when the utility grid is not connected to control voltage and frequency of the inverter, as well as techniques to avoid islanding of PV energy sources. In islanding state, the utility grid has been removed from the inverter, which then only supplies power to local loads. In addition to these standards, there are a few more among which the IEEE 1373 standard recommends practice for field test methods and procedures for grid-connected PV system, IEC 62116 standard recommends test procedure of islanding prevention measures for grid-connected PV inverters, IEC 61173 standard gives guidance on overvoltage protection for PV power generating system, IEC 61683 recommends the procedure for measuring efficiency of the PV system.

\section{THE GROWING TRENDS OF GRID- CONNECTED PV SYSTEMS}

The PV industry is expected to continue to grow due to several factors like the falling prices of silicon and PV modules, technological advancements in large scale manufacturing, many governmental incentives, maturation and proliferation of favorable interconnection agreements and continued technological improvement of power converter technologies. For example, the cost of manufacturing PV modules has reduced dramatically, from over 100 per watt in the 1970 s to less than 1.00 per watt in 2014 [6]. In fact, large-scale wholesale orders can result in prices below $\$ 0.60$ per watt [7].

Fig. 1 shows the amount of net generation of solar PV in the U.S. from 2004 to 2014. This figure backs the claims that the growing popularity of Solar PV is a trend that will continue to rise. Although our survey yielded mixed reports as to when PV solar will be at grid parity with traditional generation sources, a common underlying theme among many researchers is that this will likely happen sooner than later. The Rocky Mountain Institute recently released a report that suggests that grid parity will be achievable by 2030 [8]. Scientists at the Argonne National Lab in Illinois have argued that this may happen by 2025 while the National Renewable Energy Laboratory (NREL) have publicly suggested that due to the rapid growth of GCPVS, grid parity may even happen as early as 2017 [9].In a survey of select International Energy Agency (IEA) member countries released in 
2013, of the total installed PV systems, more than 99\% were estimated to be grid-connected. Utilityscale installations with large systems are beginning to make up for a sizable share of the PV market. In the U.S. alone, the utility sector was responsible for about two-thirds of the total new installations in the third quarter of 2014.

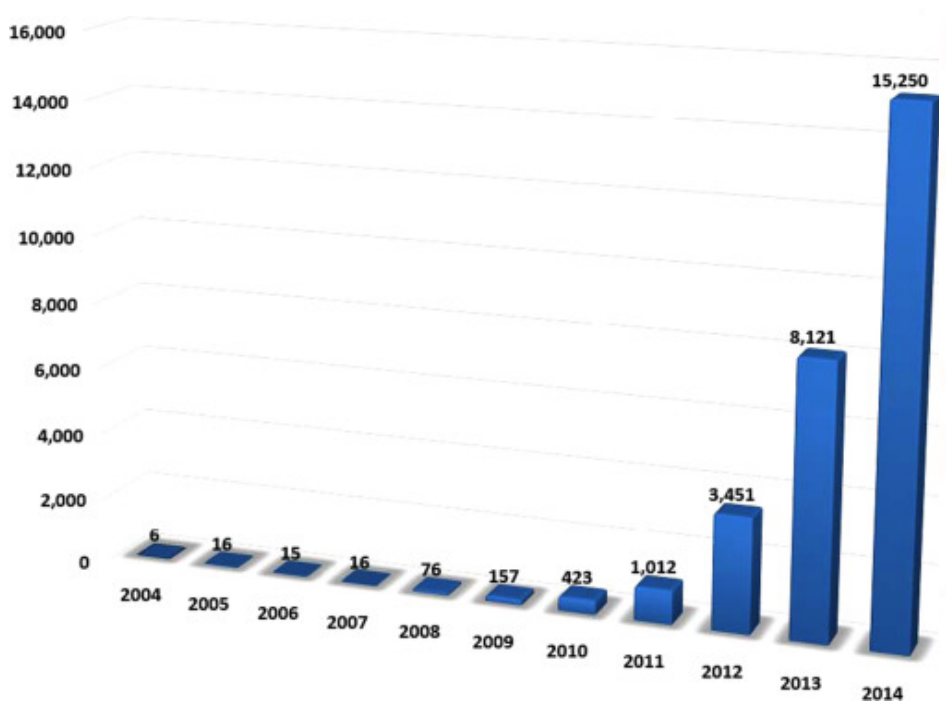

Figure 1 Net generation of solar PV in 1000's MW from 2004 to 2014

Fig. 3 represents new solar PV installations capacity in the U.S. by market segment. For the first time, in 2013, by system capacity, utility-scale installations exceeded residential and commercial installations.

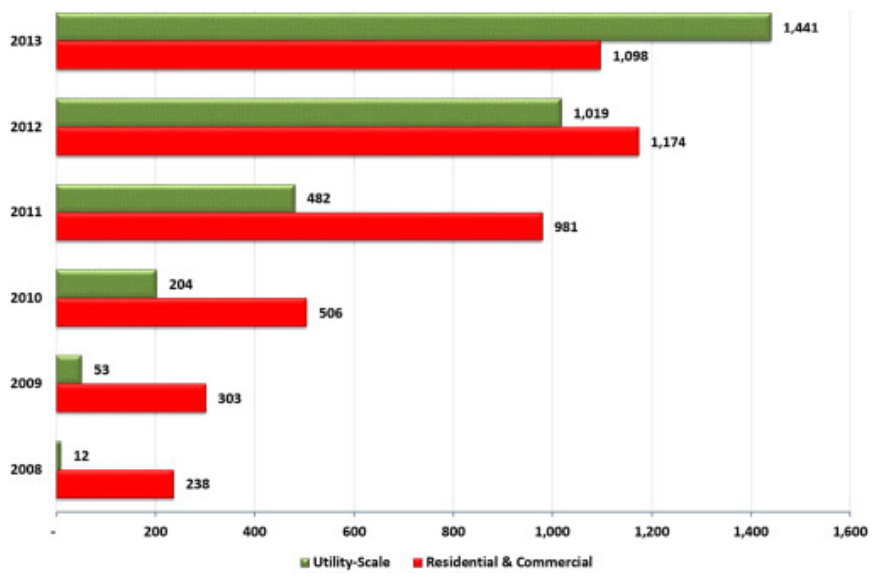

Figure 3 U.S. market segment new installation system capacity (1000's MWdc)

The rise in the number of GCPVS, especially from the utility sector, does not come as a surprise, especially given that many governmental and regulatory bodies tend to promote programs aimed at expanding DG resources like GCPVS.

\section{ISSUES CAUSED IN GRID-CONNECTED PV SYSTEMS}

As the overall costs of installing and owning GCPVS systems are declining, residential, commercial and utility scale adoption of this technology is on the rise. Although there are many benefits of GCPVS, such as its long working life (25-30 years), low operations and maintenance costs and obvious environmental advantages over fossil-fuel power plants, however, GCPVS have their own set of challenges. A number of scholarly works have suggested that the mass adoption and proliferation of GCPVS could create enormous stress on the electric grid.

The root of problem is the inherent functional nature of GCPVS, primarily because their output generation decreases as the sun goes down. Consequently, they are unable to adequately contribute to the grid when demand increases in the hours following sunset (when demand for electricity is greatest). During this period, electric utilities ramp their generation from conventional generation plants to meet this surge in demand. The California Independent System Operator (CAISO) created the duck curve (Fig. 3) to show the impact of GCPVS on the electric grid's operations based on CAISO's real-time analysis and forecast of electricity net demand from 2012 to 2020. The net demand load represents the amount of conventional generation plants (excluding renewable) that will need to be on-line during different times of the day.

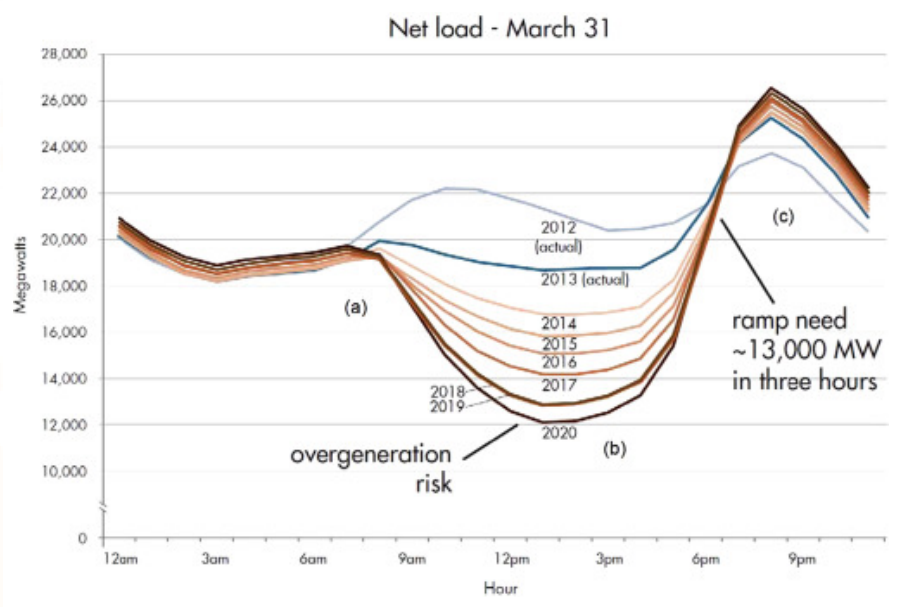

Figure 4 CAISO's duck curve

Zones (a) and (b) in the duck curve represents the morning and mid-day net demand loads respectively. Zone (b) has the least predictability because the increase in the generation from renewables (mostly 
GCPVS) will cause a reduction in conventional generation. It is also important to note that there is an increased risk of over generation in this zone. Finally, towards the end of the day, zone (c) is where conventional plants will see the most stress. The unpredictability of DG resources (especially solar and wind) means that utility providers may not be able to properly control and plan for the variable system electricity demand. According to CAISO, steep power ramps, over-generation and the resulting impact on frequency response will need to be quickly addressed as more GCPVS are installed, commissioned and connected to the grid.

There are a number of solutions to these problems. Because traditional generation resources (steam combustion turbines and nuclear plants) take hours to start and ramp up, investment in generation plants capable of fast ramping, especially gas-fired reciprocating engines and simple-cycle combustion turbines, can help mitigate the effects of the stress on the grid. Such resources serve as spinning reserves, operated on an "as-needed" basis to fill the gap created by non-dispatchable DG resources. Such new investments, however, may not be the most costeffective solution since their full nameplate capacity is rarely utilized. In addition, these facilities will take several years to plan, design and permit, and they will depend on fossil fuels.

A preferred solution may be to couple the nondispatchable DG resources like GCPVS with energy storage systems that extend their operation by an extra hour or two after the sun begins to set. Such a strategy would negate the need for rapid ramping of reserves as GCPV output begins to decreases at sunset, thereby flattening the evening peak in zone (c) of the duck curve (Fig. 3) towards zone (b).

\section{DIFFERENT TOPOLOGIES OF GRID CONNECTED PV INVERTER}

In the grid-connected PV system, the DC power of the $\mathrm{PV}$ array should be converted into the $\mathrm{AC}$ power with proper voltage magnitude, frequency and phase to be connected to the utility grid. Under this condition, a DC-to-AC converter which is better known as inverter is required. here are various kinds of grid-connected PV inverters as shown in Fig. 5. The line-commutated inverter, in which the utility grid dictates the commutation process (the commutation process is initiated by reversal of the AC voltage polarity), uses power switching devices like commutating thyristors. The turn-on operation of this device can be controlled by the gate terminal of the device while the turn-off cannot be controlled by the same. Turn-off of such device is performed with the help of an add-on circuit to the device. Contrarily, the self-commutated inverter, where the current is transferred from one switching device to another in a controlled manner, is characterized in that it uses such a power switching device, the potential at the gate terminal of which can control both the turn-on and the turn-off operation, such as Insulated Gate Bipolar Transistor (IGBT) and Metal Oxide Semiconductor Field Effect Transistor (MOSFET). Power MOSFETs are used for low power typically less than $10 \mathrm{~kW}$ and high-frequency switching operation $(20-800 \mathrm{kHz})$ and IGBTs are used for medium-to-high power exceeding $100 \mathrm{~kW}$, but very high-frequency switching is not possible using IGBTs as the switching frequency is limited to $20 \mathrm{kHz}$. In case of grid-connected inverter, highfrequency switching is required to reduce an inverter's output-current harmonics, size of the magnetic (filter) used, and weight of the inverter. The self-commutated inverter uses a pulse width modulation (PWM) switching techniques to generate an $\mathrm{AC}$ waveform at the output. The self-commutated inverter can control both voltage waveform as well as current waveform at the output side of inverter, and adjust or correct the power factor and suppress the harmonics in the current waveform which is required for gridconnected PV system, and is highly resistant to utility grid disturbances. In present days, due to evolution of advanced switching devices like Power MOSFETs and IGBTs, most inverters for distributed power systems such as PV systems now employ a selfcommutated inverters rather than line-commutated inverters.

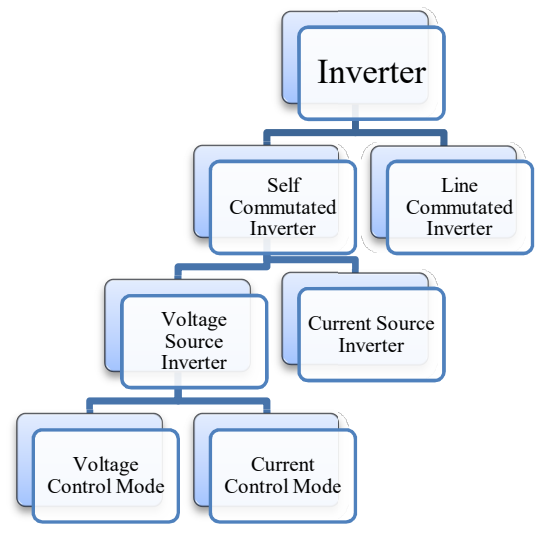

Figure - 5 Classification of inverter type 
In the self-commutated inverters may be voltage source inverter (VSI) or current source inverter (CSI) based on voltage or current waveforms at their input DC side. In VSI, the input side is a DC voltage source, the input voltage holds the same polarity, the average power flow direction through the inverter is determined by the polarity of the input DC current, and at the output side, an $\mathrm{AC}$ voltage waveform of the constant amplitude and variable width can be obtained. To limit current flow from the inverter to the utility grid a tie line inductor is used along with VSI. The input DC side terminals of a VSI are typically connected in parallel with a relatively large capacitor that resembles a voltage source.

\begin{tabular}{|c|c|c|}
\hline Parameter & Voltage Source Inverter (VSI) & Current Source Inverter (CSI) \\
\hline Power Source & $\begin{array}{l}\text { The input of VSI is a DC voltage } \\
\text { source having small or negligible } \\
\text { impedance. }\end{array}$ & $\begin{array}{l}\text { The input of a CSI is changeable current from a } \\
\text { DC voltage source having high impedance. }\end{array}$ \\
\hline Inpt parameter & $\begin{array}{l}\text { The input voltage is maintained } \\
\text { constant. The input DC side } \\
\text { terminals of a VSI are connected } \\
\text { in parallel with a capacitor and DC } \\
\text { capacitor is small, cheap and } \\
\text { efficient energy storage. }\end{array}$ & $\begin{array}{l}\text { The input current is constant but adjustable. The } \\
\text { input DC side of a CSI is connected in series } \\
\text { with an inductor, and DC inductor is bulky, } \\
\text { expensive and contributes more losses. }\end{array}$ \\
\hline Load dependency & $\begin{array}{l}\text { The amplitude of output voltage } \\
\text { does not depend on the load. } \\
\text { Contrarily, the waveform of the } \\
\text { output current as well as its } \\
\text { magnitude depends upon the } \\
\text { nature of load impedance. }\end{array}$ & $\begin{array}{l}\text { The amplitude of output current does not depend } \\
\text { on the load. Contrarily, the waveform of output } \\
\text { voltage as well as its magnitude depends upon } \\
\text { the nature of the load impedance. }\end{array}$ \\
\hline Associated losses & $\begin{array}{l}\text { High switching loss but low } \\
\text { conduction loss. Thus total power } \\
\text { loss is low. }\end{array}$ & $\begin{array}{l}\text { Low switching loss but high conduction loss. } \\
\text { Thus, the total power loss is high. }\end{array}$ \\
\hline
\end{tabular}

TABLE I.

DIFFERENCE BETWEEN VSI AND CSI [10]

In CSI, the input side is a DC current source, the input current holds the same polarity, and therefore the average power flow direction through the inverter is determined by the polarity of the input voltage and at the output side, an $\mathrm{AC}$ current waveform of the constant amplitude and variable width can be obtained. The input DC side of the CSI is typically connected in series with a relatively large inductor that maintains the current continuity. A VSI can be operated in voltage control mode as well as in currentcontrol mode and in many times, VSI with current control mode is preferred for grid-connected PV system. In Table 1, some basic differences between a VSI and a CSI are presented.

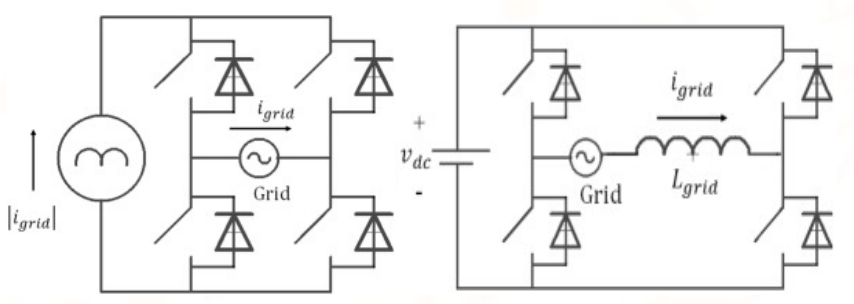

Figure 2(A) Line-commutated

Figure 2(B) Self Commutated

Fig. 2(A), Fig. 2(B) shows configurations of linecommutated CSI and self-commutated VSI.

For the inverter of stand-alone PV system without any grid connection, voltage control mode should be used. However, both voltage control mode and current control mode can be used for the inverter of gridconnected PV system. In grid-connected PV system, inverter with the current control mode is extensively 
used because a high power factor can be obtained by a simple control circuit, and also suppression of transient current is possible when any grid disturbances occur.

\section{CONCLUSIONS}

Although the solar PV market has experienced astronomical levels of growth and cost reductions in recent years, there are many technical challenges and economic realities that need to be reconciled in order for DG resources like GCPVS to be at parity with conventional generation. For successful mass adoption of GCPVs, new technologies must be developed that will allow the inverter to do more than just provide DC/AC conversions. Modern gridinteractive inverters will need to provide Volt/VAR control (power factor and voltage stabilization), frequency regulation, enable storage and utilize modern communications protocols, all at a reasonable cost. This new generation of inverters has been rightly termed "smart inverters".

Future GCPVS design will require inverters to monitor, react to and adjust their output based on instantaneous feedback from the grid. The inverter will also be able to save and share data with the facility management system for trending, predictive, preventative and corrective maintenance. These new breed of smart inverters will be able to log several data like available battery storage hours and capacity information, alarm on external events and provide day to day power management information. Rethinking the role and capability of the inverters can foster the mass adaption of GCPVS and equally help to create and support a more reliable grid.

\section{REFERENCES}

[1] G. Ishikawa T, "Grid-connected photovoltaic power systems: survey of inverter and related protection equipments". Report IEA (International Energy Agency) PVPS T5-05; 2002.

[2] Trends in Photovoltaic Applications. Survey report of selected IEA countries between 1992 and 2013. Photovoltaic. Power Systems Program, Report IEA-PVPS T1-13; 2014; 2014.
[3] U.S. Energy Information Agency. United States electricity profile. Summary statistics for supply and disposition of electricity, 1990-2012; 2012.

[4] Wong L. "A review of transmission losses in planning studies". Technical report. Electricity Analysis Office, Electricity Supply Analysis Division, California Energy Commission; August 2011.

[5] Verhoeven B. "Utility Aspects of Grid Connected Photovoltaic Power Systems. International Energy Agency Photovoltaic Power Systems", IEA PVPS T501: 1998. [Online]. Available: www.iea-pvps.org et al.. 1998 .

[6] Feldman G, Barbose D, Margolis R, Wiser R, Darghouth N, Goodrich A. "Photovoltaic (PV) pricing trends: historical, recent, and near-term projections". Technical report. National Renewable Energy Laboratory (NREL); [November 1, 2012], Issue: DOE/GO-102012-3839.

[7] Mehta S. Analyst alert: solar PV pricing on the rise. Greentech Media; 2013.

[8] Peter Bronski, Jon Creyts, Leia Guccione, Maite Madrazo, James Mandel, Bodhi Rader, et al.'The economics of grid defection when and where distributed solar generation plus storage competes with traditional utility service", Rocky Mountain Institute, Boulder, CO (2014).

[9] Koerth-Baker M. Shining light on the cost of solar energy. National Geographic; 2010.

[10] Azmi SA; Dept. of Electron. \& Electr. Eng., Univ. of Strathclyde, Glasgow, UK; K. H. Ahmed; S. J. Finney; B. W. Williams, "Comparative analysis between voltage and current source inverters in gridconnected application". In: Proceedings of IET Conference on Renewable Power Generation (RPG 2011); 6-8 Sept. 2011. P. 1-6. 